\title{
Study on the Creep Constitutive Model of a Sandstone Rock under the Water-Rock Interaction
}

\author{
Zuosen Luo $\mathbb{D}^{1,2}$ Zuoxiang Zhu, ${ }^{2}$ Jianlin Li, ${ }^{2}$ Lehua Wang, ${ }^{2}$ Qiao Jiang, ${ }^{3}$ Jingyu Zhang $\left(\mathbb{D}^{2}\right.$, \\ Eleyas Assefa, ${ }^{4}$ and Huafeng Deng ${ }^{2}$ \\ ${ }^{1}$ Engineering Research Center of Eco-environment in Three Gorges Reservoir Region, Ministry of Education, \\ China Three Gorges University, Yichang 443002, China \\ ${ }^{2}$ Key Laboratory of Geological Hazards on Three Gorges Reservoir Area of Ministry of Education, China Three Gorges University, \\ Yichang, Hubei 443002, China \\ ${ }^{3}$ China Three Gorges Projects Development Co., Ltd., Chengdu, Sichuan 610041, China \\ ${ }^{4}$ College of Architecture and Civil Engineering, Addis Ababa Science and Technology University, 1000 Addis Ababa, Ethiopia
}

Correspondence should be addressed to Zuosen Luo; lzs@ctgu.edu.cn

Received 10 December 2020; Revised 11 January 2021; Accepted 4 March 2021; Published 17 March 2021

Academic Editor: Xingzhou Chen

Copyright (c) 2021 Zuosen Luo et al. This is an open access article distributed under the Creative Commons Attribution License, which permits unrestricted use, distribution, and reproduction in any medium, provided the original work is properly cited.

With the continuous construction of large-scale geotechnical engineering, more and more attention has been paid to the longterm stability of rock mass engineering, especially the problem of rock creep under the influence of water. Combined with the author's previous research on the triaxial creep characteristics of sandstone under water-rock interaction, a nonlinear creep constitutive model was established to capture the degradation behavior of a sandstone rock due to cyclic wetting and drying of the reservoir water. Due to the limitations of the visco-elastoplastic model, a thorough modification was done to account the effect of the water-rock interaction on the mechanical degradation of the sandstone rock. Finally, the predicted results were proved to be in a good agreement with the experimental results. Moreover, the strong correlations between the predicted results and the experimental results show the effectiveness of the modified model to scrutinize the nonlinear creep behavior of sandstone rock. Relevant research results have important theoretical significance for the accurate prediction and effective control of the long-term stability of rock mass engineering under the influence of water-rock interaction.

\section{Introduction}

After the completion of the Three Gorges Hydropower Project, the reservoir water level has been fluctuating by $30 \mathrm{~m}$ (between $145 \mathrm{~m}$ and $175 \mathrm{~m}$ ). The Three Gorges reservoir has $600 \mathrm{~km}$ length. It inundates 4 counties in Hubei Province and 16 counties in Chongqing. The reservoir bank slope in the hydrofluctuation zone is subsequently altered by the wetting and drying cycles. This phenomenon has an adverse effect on the mechanical properties of the rock mass [1-5]. According to statistics, more than 1,190 landslides have occurred in the Three Gorges reservoir area [6]. After the commencement of the Three Gorges project, plenty of progressive deformations have been developing in the reservoir bank slopes. Typical landslides were reported in 2008 and 2009. For instance, the Goyang and the Liangshuijing landslides occurred in 2008 and 2009, respectively. The deformation and the failure of the reservoir bank slopes are mainly due to the effect of the water-rock interaction on the creep mechanical properties of the rock mass [7-10].

There have been significant advances in developing constitutive models for the rock creep test. Rock creep phenomenon is getting a wide attention [11-13]. The deterioration of rock and soil properties effect of water is also a hot issue [14-16]. The effect of water on the rock creep behavior has been studied by different investigators. According to Wawersik and Brown, the effect of water on the time dependent deformation behavior of granite and sandstone rocks was increasing when the moisture content increased. Under uniaxial stress, the rate of steady-state 
creep for dry and saturated specimens differs by two orders of magnitude [17]. Zhu Hehua and Ye Bin [18] conducted uniaxial creep tests on dry and saturated tuff rock. According to their finding, water has a significant impact on the ultimate creep behavior of tuff rock. The ultimate creep values showed 5-6-fold differences in dry and saturated specimens. Under uniaxial creep test, the long-term strength of saturated granite was decreasing when the creep and the strain rates significantly increased [19]. Liu et al. [20] conducted both uniaxial and biaxial creep tests on soft conglomerates. In the above study, the rheological deformation of saturated conglomerates was about 10 -fold of the saturated ones at the same stress levels. Liu Lang [21] conducted a creep test on the deep-saturated rock mass in Dongguashan Mountain using single-stage and gradient incremental cyclic loadings. The rock creep characteristics of both dry and saturated specimens were found to be high. Deng et al. [22] conducted conventional triaxial compression and creep tests on redbed soft rocks. According to the above studies, water plays a significant role in the rock creep properties. Recently, many scholars have proposed a number of constitutive models based on the creep test results of different kinds of rocks [23-26]. Some researchers introduced the water content parameter into the creep constitutive models to scrutinize the effect of water on the degradation mechanism of rocks [27-29]. Further research is important to understand the long-term effect of water on the creep behavior of rocks.

In this paper, the degradation effect of water-rock interaction on the mechanical properties of the rock was considered, the sandstone creep constitutive relationship considering the water-rock interaction was established, and the research results can provide references for specific engineering calculations and analysis.

\section{Creep Characteristics of Sandstone under Water-Rock Interaction}

Typical triaxial creep test results of sandstone rock are presented in Luo et al.'s research [30]. According to the analysis of the creep test results, it can be seen that the creep curve of sandstone has the following characteristics:

(1) The sandstone sample in the test has instantaneous elastic strain and instantaneous elastic deformation at the moment of stress loading. At this stage, a spring element can be used to simulate its deformation characteristics.

(2) After the sandstone sample completes the instantaneous deformation, creep deformation occurs. The amount of deformation slowly increases with time, and the strain rate slowly decreases. It enters the attenuation creep and stable creep stage of the rock, and the creep curve is concave upward. The deformation characteristics of the first stage can be simulated with viscoelastic elements.

(3) When the constant stress carried by the sandstone sample is smaller than the long-term strength, only the attenuation creep stage and the stable creep stage occur. At this time, the creep is stable creep; and when the constant load is greater than (or equal to) the long-term strength, the sandstone sample will develop in the direction of unstable creep. At this time, the rock will undergo irreversible plastic flow deformation. The creep at this stage can be simulated by viscous elements. Since there is a limit (long-term strength) from stable to unstable change, a switch element can be used to represent this limit, and a viscoplastic element with a switch can be used to represent the creep deformation characteristics at this stage.

(4) When the constant load is greater than its long-term strength, the sandstone sample enters the accelerated creep stage after a period of constant creep. The deformation characteristics of this stage are nonlinear. Consider using nonlinear elements to simulate these deformation characteristics of the stage.

\section{Creep Constitutive Model}

3.1. Advantages and Limitations of the Visco-Elastoplastic Model. The conventional Nishihara model (Figure 1) consists of the Hokkaido $(\mathrm{H})$, the viscoelastic $(\mathrm{N} / \mathrm{H})$, and the viscoplastic $\left(\mathrm{N} /\right.$ St. V), where $E_{1}$ is the elastic modulus, $E_{2}$ is the viscoelastic modulus, and both $\eta_{1}$ and $\eta_{2}$ are the viscosity coefficients of the dashpots.

The visco-elastoplastic model can be used to represent the creep characteristics of a sandstone rock. The viscoelastoplastic model has elastic-viscoelastic-viscoplasticity characteristics, which can comprehensively reflect the entire rock creep characteristics. Apart from that, it has the following limitations: (1) it cannot reflect the nonlinearly accelerated rock creep stage and (2) it cannot consider the effect of water on the mechanical degradation of the rock.

3.2. Modification of the Creep Stage. In order to establish a constitutive model that describes the nonlinear creep characteristics of sandstone rock, a nonlinear viscoplastic rheological element is introduced here, as shown in Figure 2.

Under the action of $\sigma$, the expression for the nonlinear viscoplastic element is

$$
\varepsilon=\frac{\sigma}{\eta_{3}}\left(t-t_{0}\right),
$$

where $\eta_{1}$ stands for the viscosity of nonlinear viscous element and $t_{0}$ represents the initial time. To address the mechanical damage that occurs during the nonlinear creep failure of the rock, another parameter $\eta_{3}$ is introduced as shown in the following equation:

$$
\eta_{3}=\eta_{s}(1-D),
$$

where $\eta_{s}$ is the viscous coefficient of a nonlinear viscous component without the mechanical damage and $D$ is the mechanical damage variable of rock. According to Wang Yu et al. [31], the internal mechanical damage variable of rock can be defined by using 


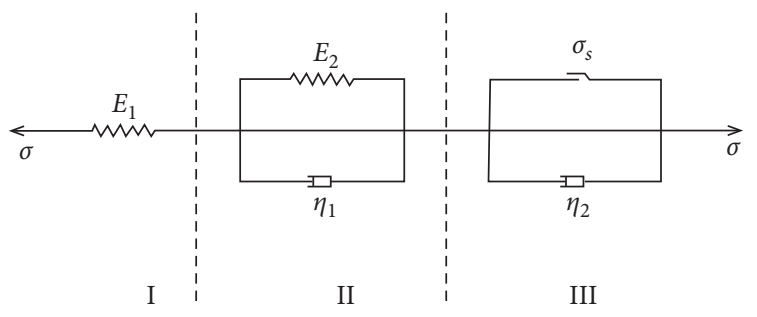

Figure 1: Components of Nishihara model.

$$
D= \begin{cases}1-e^{-\left(t-t_{0}\right)^{n},}, & t \geq t_{0}, \\ 0, & t<t_{0},\end{cases}
$$

where $n$ is a constant. When the time $t<t_{0}$, the rock sample will be in a steady-state creep phase and the damage factor $D$ will approach to zero. In the other case, when the time $t \geq t_{0}$, the rock will start a nonlinearly accelerated creep phase. At this stage, the damage variable $D$ will gradually increase with time till it gets 1 .

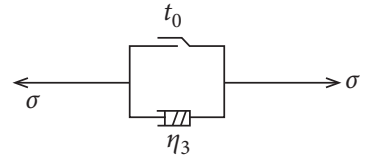

FIGURE 2: Diagram of a nonlinearly accelerated creep stage.

To address the previously stated mechanical damage by using a viscoelastic model, the damage variable was introduced into the viscosity coefficient of the viscous element in the accelerated creep stage. A nonlinear viscous element was proposed. The stress and the time can be used as the triggering conditions for the nonlinear viscous element to form a new nonlinearly accelerated creep model. After combining this with the visco-elastoplastic model, a new nonlinear viscoelastic-plastic creep model is established, as shown in Figure 3.

The corresponding creep equation is given in equation (4) as shown below:

$$
\varepsilon= \begin{cases}\frac{\sigma}{E_{1}}+\frac{\sigma}{E_{2}}\left(1-e^{-\left(E_{2} / \eta_{1}\right) t}\right), & \sigma<\sigma_{s}, \\ \frac{\sigma}{E_{1}}+\frac{\sigma}{E_{2}}\left(1-e^{-\left(E_{2} / \eta_{1}\right) t}\right)+\frac{\sigma-\sigma_{s}}{\eta_{2}} t, & \sigma \geq \sigma_{s}, t<t_{0}, \\ \frac{\sigma}{E_{1}}+\frac{\sigma}{E_{2}}\left(1-e^{-\left(E_{2} / \eta_{1}\right) t}\right)+\frac{\sigma-\sigma_{s}}{\eta_{2}} t_{0}+\frac{\sigma-\sigma_{s}}{\eta_{s}(1-D)}\left(t-t_{0}\right), & \sigma \geq \sigma_{s}, t \geq t_{0},\end{cases}
$$

where $E_{1}$ and $E_{2}$ are the elastic modulus of elastic and viscoelastic body, $\eta_{1}, \eta_{2}$, and $\eta_{3}$ are coefficients of viscosity for the viscoelastic body, the viscoplastic body, and the nonlinear viscous components, $\sigma_{s}$ is the rock's long-term strength, and $t_{0}$ is the initial time.

\subsection{Incorporating the Effect of Water into the Creep Model}

3.3.1. Definition of Damage Variable due to the Water-Rock Interaction. Cyclic water-rock interactions can affect the creep properties of sandstone rock. Wetting and drying cycles of the reservoir water can develop microcracks on the sandstone rock. Consequently, the cementation and the mineralogical compositions of the rock will be altered. As a result, there will be a significant change in the macroscopic mechanical parameters (the elastic modulus, the rate of deformation, and the peak intensity). According to the theory of damage mechanics, there are two main definitions of damage variables: the first one is the damage variable defined in terms of the geometric damage on the effective bearing area of the structure; and the other one is defined as the change in the elastic modulus with energy loss. This method considers the elastic property deterioration as the main cause of the failure. In this study, the damage variables were defined based on the latter definition. Here, both the elastic and the viscous coefficients were considered as the damage variables, and the macroscopic mechanical parameters (such as elastic modulus and viscous coefficient) were used to characterize the effect of water-rock interactions on the mechanical damage. The effect of water-rock interaction on the rock damage after the $N^{\text {th }}$ cycle is defined as follows:

$$
\begin{aligned}
& d_{E N}=1-\frac{E_{N}}{E_{0}}, \\
& d_{\eta N}=1-\frac{\eta_{N}}{\eta_{0}},
\end{aligned}
$$

where the parameters $E_{N}$ and $E_{0}$ stand for the elastic modulus of the sandstone at the $N^{\text {th }}$ and the initial cycles, respectively, and $\eta_{N}$ and $\eta_{0}$ are the viscosities of the sandstone at the $N^{\text {th }}$ and the initial cycles, respectively.

3.3.2. Establishing a Versatile Creep Constitutive Model. A damage variable was introduced into the earlier creep constitutive model by considering the effect of water on the degradation mechanism of the sandstone rock in the Three Gorges reservoir. The mechanical model is shown in Figure 4. 


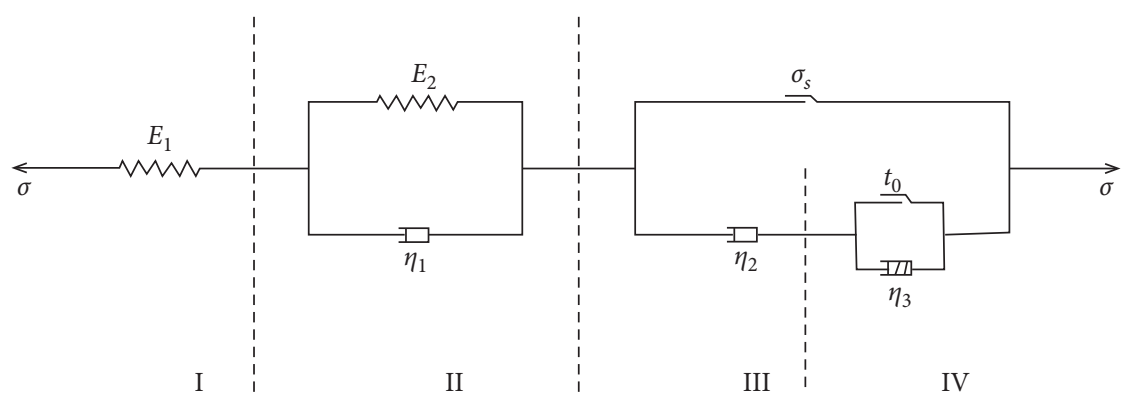

FIgURe 3: Modified visco-elastoplastic model.

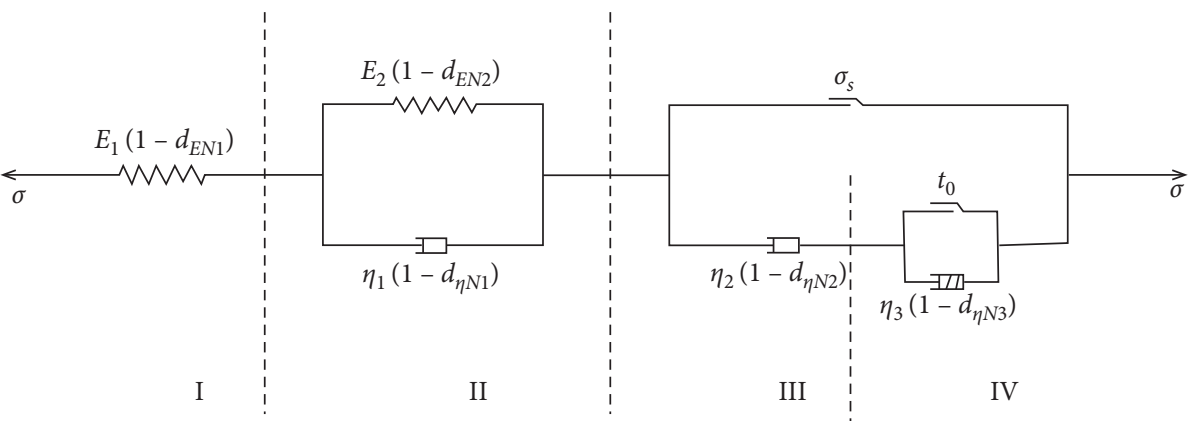

FIGURE 4: Constitutive model for a sandstone rock (considering the effect of water).

Initially, the transient elastic strain was developed by the rock loading (Figure 4), that is, the first part of the constitutive model, so that the damage due to the water-rock interaction can be defined by $d_{E N 1}$. When the stress level is low, the sample will exhibit creep deceleration and the rate of creep will gradually approach to zero. This phase corresponds to the second part of the constitutive model; hence the water-rock damage at this stage can be expressed as $d_{E N 2}$ and $d_{\eta N 1}$. When the stress level is greater than or equal to the long-term strength, the strain rate will gradually approach to a nonzero constant. The creep deceleration phase was followed by the steady creep phase. Similarly, this stage corresponds to the third part of the constitutive model; therefore, the water-rock damage was defined as $d_{\eta N 2}$. The progressive mechanical damage on the rock specimen resulted in failure. This stage corresponds to the fourth part of the constitutive model; here again the water-rock damage was introduced as $d_{\eta N 3}$.

In summary, the one-dimensional creep constitutive model for the sandstone rock considering the effect of waterrock interactions can be expressed by using the following equation:

$$
\varepsilon=\left\{\begin{array}{l}
\frac{\sigma}{E_{1}\left(1-d_{E N 1}\right)}+\frac{\sigma}{E_{2}\left(1-d_{E N 2}\right)}\left(1-e^{-\left(E_{2} \cdot\left(1-d_{E N 2}\right) / \eta_{1} \cdot\left(1-d_{\eta N 1}\right)\right) t}\right), \\
\frac{\sigma}{E_{1}\left(1-d_{E N 1}\right)}+\frac{\sigma}{E_{2}\left(1-d_{E N 2}\right)}\left(1-e^{-\left(E_{2} \cdot\left(1-d_{E N 2}\right) / \eta_{1} \cdot\left(1-d_{\eta N 1}\right)\right) t}\right)+\frac{\sigma-\sigma_{s}}{\eta_{2}\left(1-d_{\eta N 2}\right)} t, \\
\frac{\sigma}{E_{1}\left(1-d_{E N 1}\right)}+\frac{\sigma}{E_{2}\left(1-d_{E N 2}\right)}\left(1-e^{-\left(E_{2} \cdot\left(1-d_{E N 2}\right) / \eta_{1} \cdot\left(1-d_{\eta N 1}\right)\right) t}\right)+\frac{\sigma-\sigma_{s}}{\eta_{2}\left(1-d_{\eta N 2}\right)} t_{0}+\frac{\sigma-\sigma_{s}}{\eta_{s}(1-D)\left(1-d_{\eta N 3}\right)}\left(t-t_{0}\right) \sigma \geq \sigma_{s}, \quad t \geq t_{0} .
\end{array}\right.
$$

Under normal circumstances, the rock is in a complex and three-dimensional stress state. Therefore, it is of great significance to establish a three-dimensional creep constitutive model. The one-dimensional creep equation can be transformed into a more general three-dimensional form, by using the normal bulk modulus and Poisson's ratio methods.
In this paper, the ordinary bulk modulus method is used to derive the one-dimensional creep equation.

Under the condition of three-dimensional stress, the stress tensors can be decomposed into global stress tensor $\sigma_{m}$ and the deviatoric stress tensor $S_{i j}$, and the expressions are as follows: 
TABLE 1: Identified parameters for the nonlinear creep constitutive model.

\begin{tabular}{|c|c|c|c|c|c|c|c|c|}
\hline Cycles & Direction & Load level & $\left(G_{1} / G P_{a}\right)$ & $\left(G_{2} / G P_{a}\right)$ & $\eta_{1} /\left(G P_{a} \cdot h^{-1}\right)$ & $\eta_{2} /\left(G P_{a} \cdot h^{-1}\right)$ & $\eta_{3} /\left(G P_{a} \cdot h^{-1}\right)$ & $R^{2}$ \\
\hline \multirow{10}{*}{0} & \multirow{6}{*}{ Axial } & First step & 2.19 & 7.10 & 21.44 & - & - & 0.99 \\
\hline & & Second step & 2.82 & 4.83 & 24.49 & - & - & 0.99 \\
\hline & & Third step & 1.88 & 4.13 & 24.06 & - & - & 0.99 \\
\hline & & Fourth step & 10.41 & 4.54 & 10.17 & - & - & 0.99 \\
\hline & & Fifth step & 12.58 & 6.81 & 8.84 & 2.08 & 5.45 & 0.98 \\
\hline & & First step & 14.45 & 2.44 & 65.83 & - & - & 0.99 \\
\hline & \multirow{4}{*}{ Lateral } & Second step & 27.37 & 2.71 & 55.31 & - & - & 0.99 \\
\hline & & Third step & 3.95 & 1.90 & 28.00 & - & - & 0.99 \\
\hline & & Fourth step & 4.11 & 1.90 & 11.70 & - & - & 0.99 \\
\hline & & Fifth step & 4.11 & 6.79 & 9.47 & 0.52 & 10.62 & 0.98 \\
\hline \multirow{10}{*}{2} & \multirow{5}{*}{ Axial } & First step & 0.82 & 5.2 & 12.8 & \multirow{5}{*}{396.0} & \multirow{5}{*}{32.4} & 0.96 \\
\hline & & Second step & 0.98 & 3.9 & 9.4 & & & 0.97 \\
\hline & & Third step & 5.7 & 2.8 & 8.7 & & & 0.97 \\
\hline & & Fourth step & 1.8 & 1.3 & 6.3 & & & 0.99 \\
\hline & & Fifth step & 9.3 & 5.0 & 763.3 & & & 0.98 \\
\hline & \multirow{6}{*}{ Lateral } & First step & 3.9 & 2.7 & 47.5 & \multirow{5}{*}{111.9} & \multirow{5}{*}{7.6} & 0.98 \\
\hline & & Second step & 2.5 & 2.4 & 22.6 & & & 0.99 \\
\hline & & Third step & 1.6 & 1.5 & 10.2 & & & 0.98 \\
\hline & & Fourth step & 0.97 & 0.45 & 3.3 & & & 0.97 \\
\hline & & Fifth step & 450.6 & 3.4 & 516.8 & & & 0.99 \\
\hline \multirow{8}{*}{6} & & First step & 54.5 & 0.68 & 2.1 & \multirow{4}{*}{43.9} & \multirow{4}{*}{63.6} & 0.99 \\
\hline & \multirow{3}{*}{ Axial } & Second step & 0.86 & 2.6 & 12.8 & & & 0.98 \\
\hline & & Third step & 1.0 & 1.1 & 18.9 & & & 0.99 \\
\hline & & Fourth step & 2.7 & 3.6 & 20.9 & & & 1.00 \\
\hline & \multirow{5}{*}{ Lateral } & First step & 26.4 & 1.9 & 11.3 & \multirow{4}{*}{73.5} & \multirow{4}{*}{1.9} & 0.98 \\
\hline & & Second step & 4.4 & 1.1 & 13.7 & & & 0.98 \\
\hline & & Third step & 1.3 & 0.24 & 6.5 & & & 0.99 \\
\hline & & Fourth step & 11.3 & 4.6 & 677.5 & & & 1.00 \\
\hline \multirow{8}{*}{10} & & First step & 0.61 & 3.0 & 4.0 & \multirow{4}{*}{246.3} & \multirow{4}{*}{29.7} & 0.99 \\
\hline & \multirow{3}{*}{ Axial } & Second step & 1.4 & 3.5 & 9.6 & & & 0.98 \\
\hline & & Third step & 0.78 & 1.2 & 9.1 & & & 0.99 \\
\hline & & Fourth step & 63.9 & 1.2 & 17.3 & & & 1.00 \\
\hline & \multirow{4}{*}{ Lateral } & First step & 0.88 & 3.8 & 2.6 & \multirow{4}{*}{62.1} & \multirow{4}{*}{6.8} & 0.99 \\
\hline & & Second step & 5.1 & 1.4 & 9.7 & & & 0.98 \\
\hline & & Third step & 18.5 & 0.33 & 3.6 & & & 0.98 \\
\hline & & Fourth step & 0.9 & 711.1 & 14.8 & & & 1.00 \\
\hline
\end{tabular}

$$
\left\{\begin{array}{l}
\sigma_{m}=\frac{1}{3}\left(\sigma_{1}+\sigma_{2}+\sigma_{3}\right)=\frac{\sigma_{k k}}{3}, \\
S_{i j}=\sigma_{i j}-\delta_{i j} \sigma_{m}=\sigma_{i j}-\frac{1}{3} \delta_{i j} \sigma_{k k} .
\end{array}\right.
$$

We have

$$
\sigma_{i j}=S_{i j}+\delta_{i j} \sigma_{m}
$$

The strain tensors can also be decomposed into the global strain tensor $\varepsilon_{m}$ and the bias strain tensor $e_{i j}$, where

$$
\left\{\begin{array}{l}
\varepsilon_{m}=\frac{1}{3}\left(\varepsilon_{1}+\varepsilon_{2}+\varepsilon_{3}\right)=\frac{\varepsilon_{k k}}{3}, \\
e_{i j}=\varepsilon_{i j}-\delta_{i j} \varepsilon_{m}=\varepsilon_{i j}-\frac{1}{3} \delta_{i j} \varepsilon_{k k} .
\end{array}\right.
$$

Similarly,

$$
\varepsilon_{i j}=e_{i j}+\delta_{i j} \varepsilon_{m}
$$

Introducing the bulk modulus $K$ and the shear modulus $G$,

$$
\begin{aligned}
& K=\frac{E}{3(1-2 v)}, \\
& G=\frac{E}{2(1+v)},
\end{aligned}
$$

where $E$ and $v$ represent the elastic modulus and Poisson's ratio of the rock, respectively. For three-dimensional state of stress, we have

$$
\left\{\begin{array}{l}
\sigma_{m}=3 K \varepsilon_{m}, \\
S_{i j}=2 G e_{i j},
\end{array}\right.
$$

where $\sigma_{m}$ is the global stress tensor, $S_{i j}$ is the deviatoric stress tensor, $\varepsilon_{m}$ is the strain tensor, and $e_{i j}$ is the deviatoric strain tensor.

Then the three-dimensional creep constitutive equation is summarized in the following equation: 


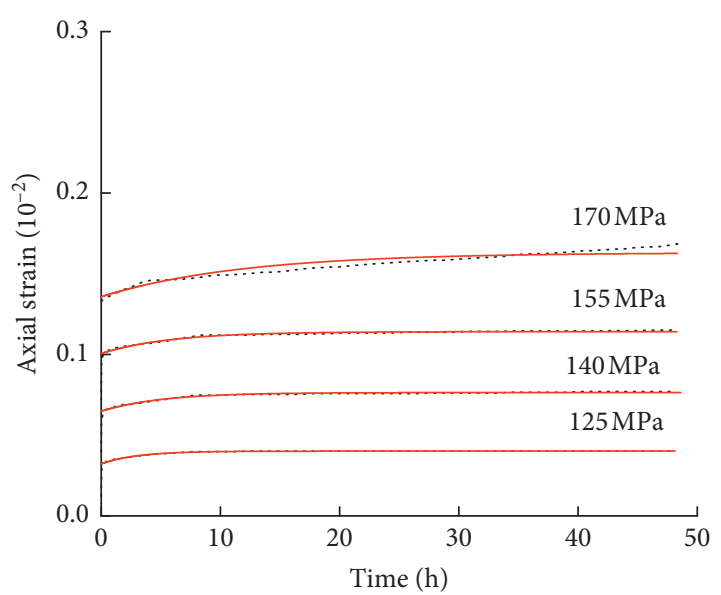

.... Experimental values

_ Calculated values

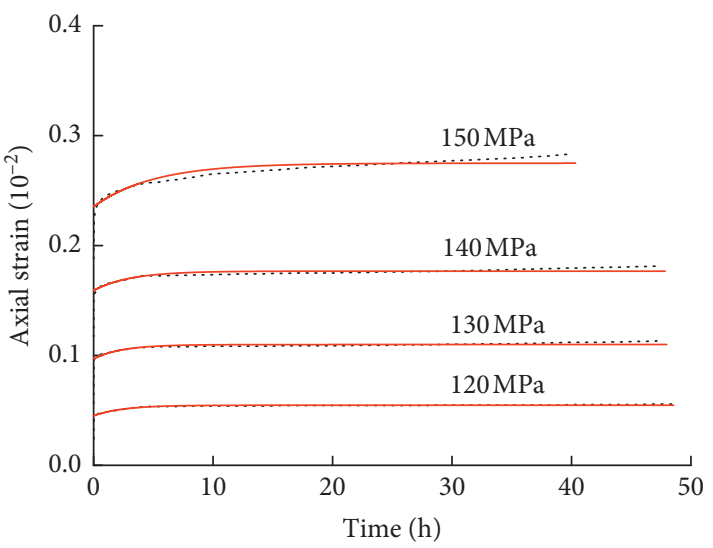

..... Experimental values

_ Calculated values

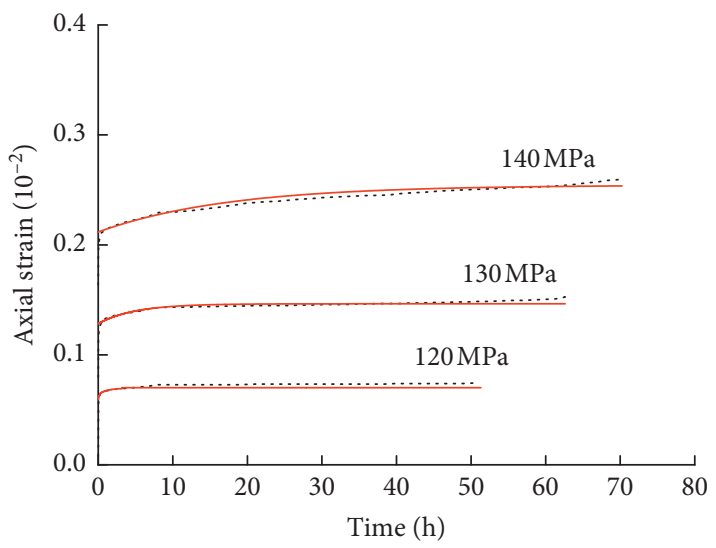

Experimental values

Calculated values

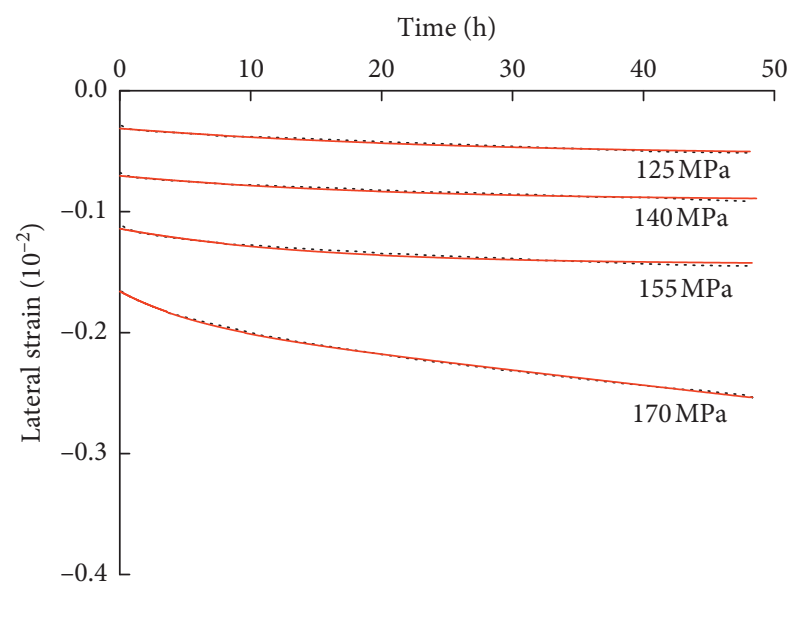

.... Experimental values

_ Calculated values

(a)

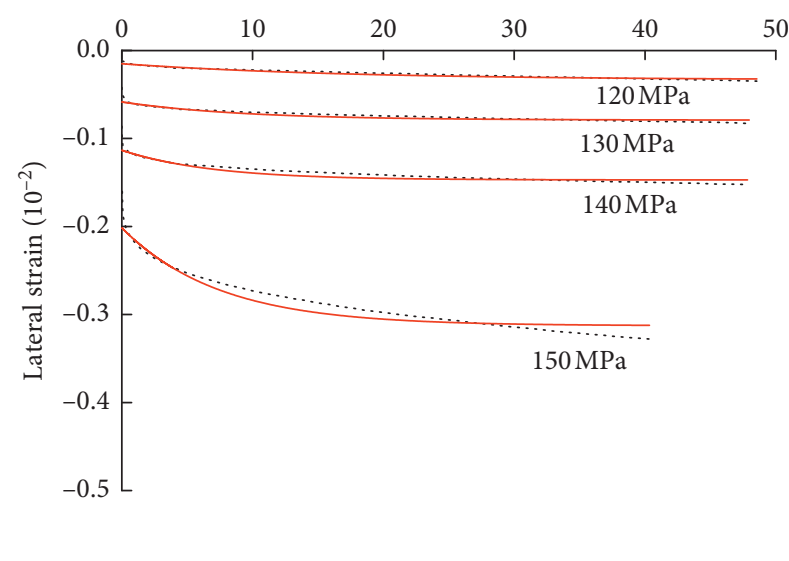

...... Experimental values

_ Calculated values

(b)

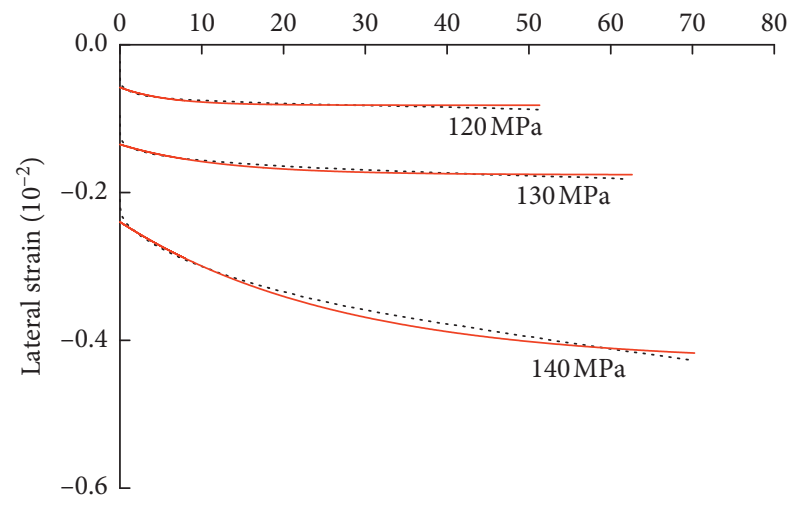

Experimental values

Calculated values

(c)

Figure 5: Continued. 

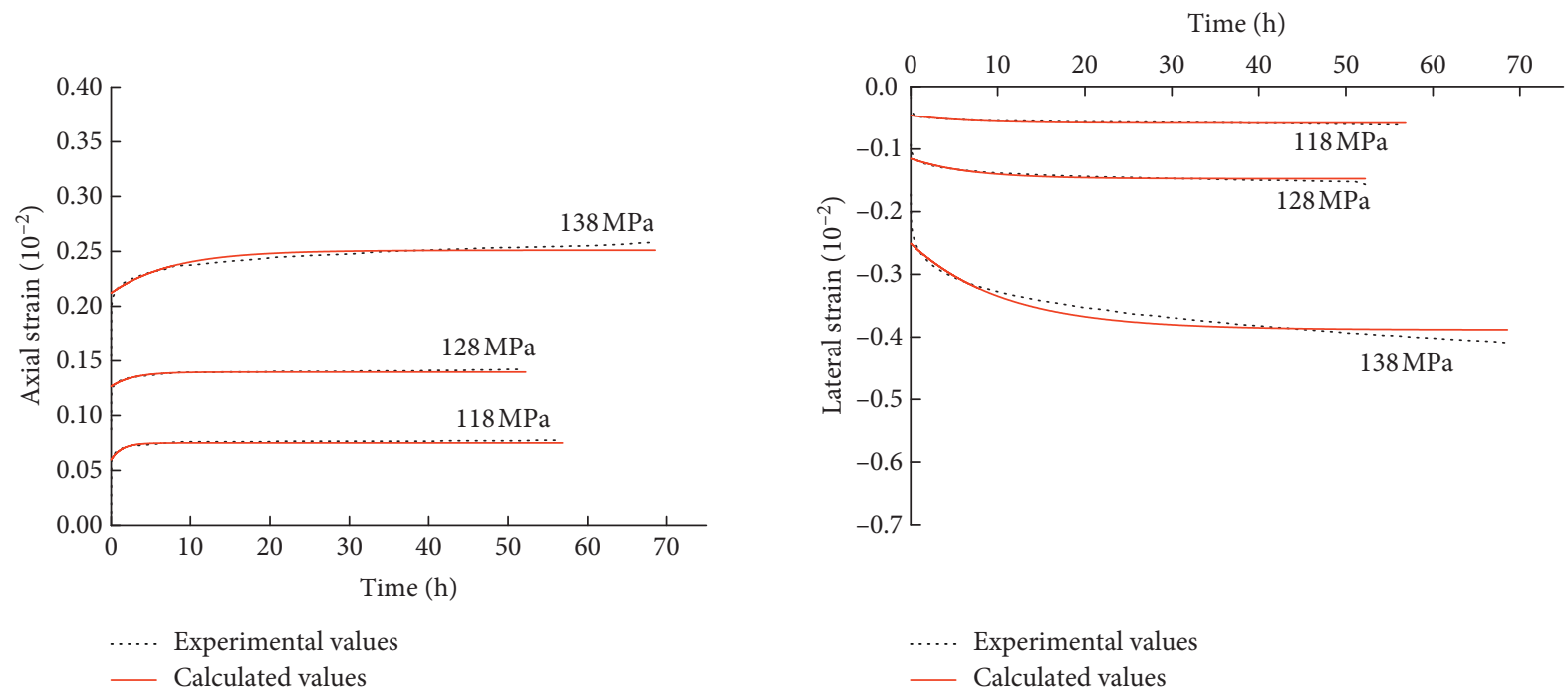

(d)

FIGURe 5: Relationships between the experimental and the calculated values at the low stress level. (a) $0^{\text {th }}$ cycle. (b) $2^{\text {nd }}$ cycle. (c) $6^{\text {th }}$ cycle. (d) $10^{\text {th }}$ cycle.
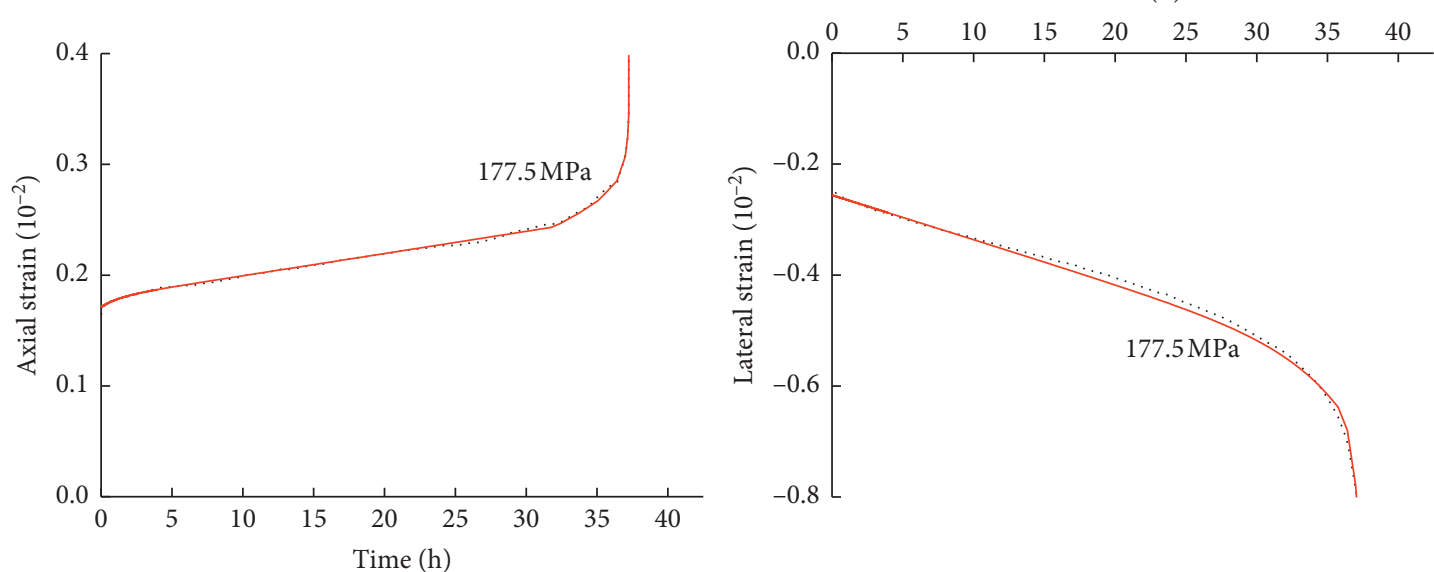

..... Experimental values

.... Experimental values

_ Calculated values

_ Calculated values

(a)

Figure 6: Continued. 


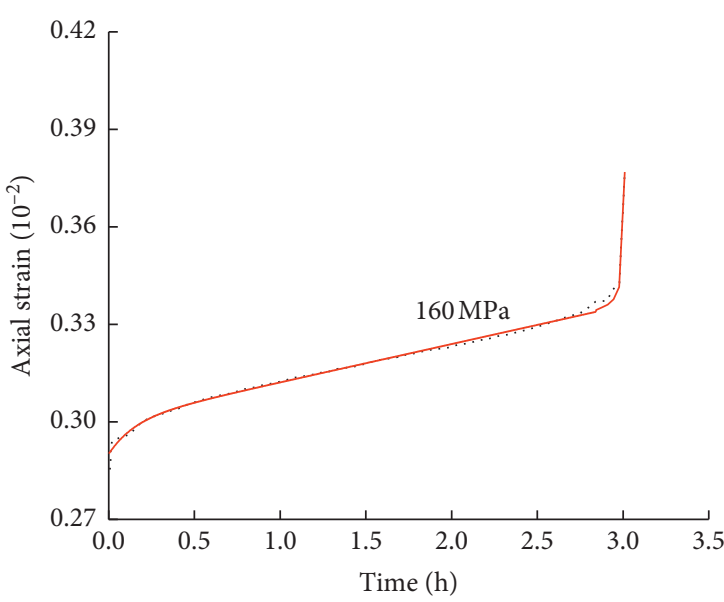

..... Experimental values

_ Calculated values

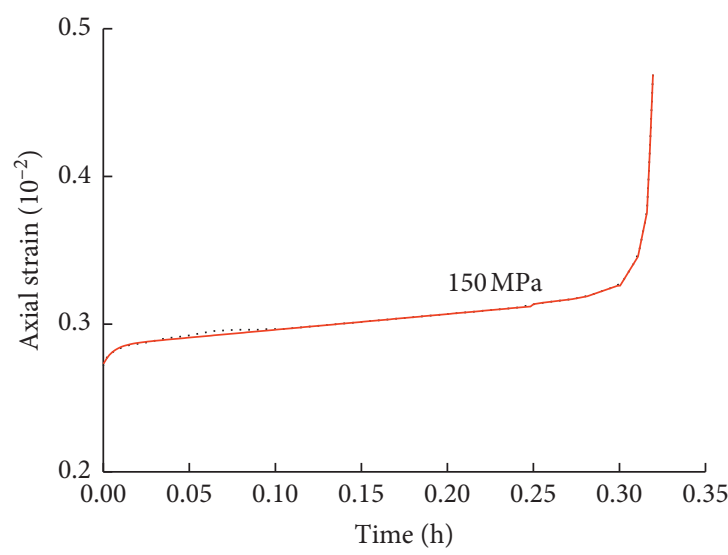

..... Experimental values

- Calculated values

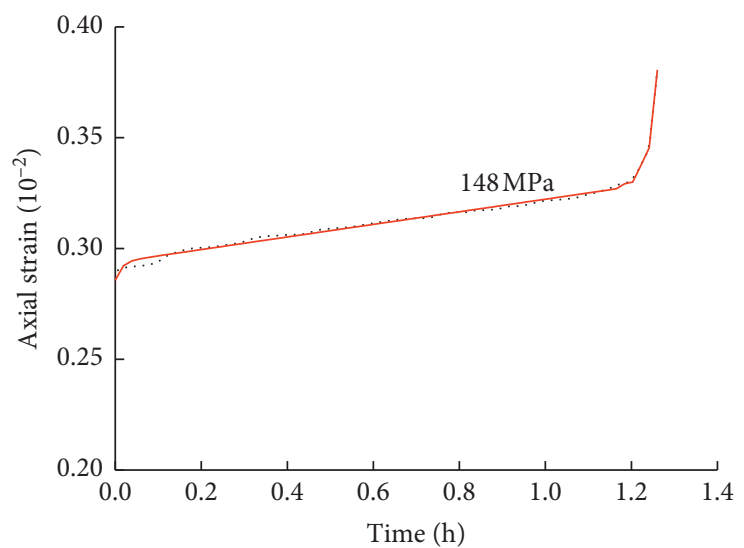

Experimental values

Calculated values

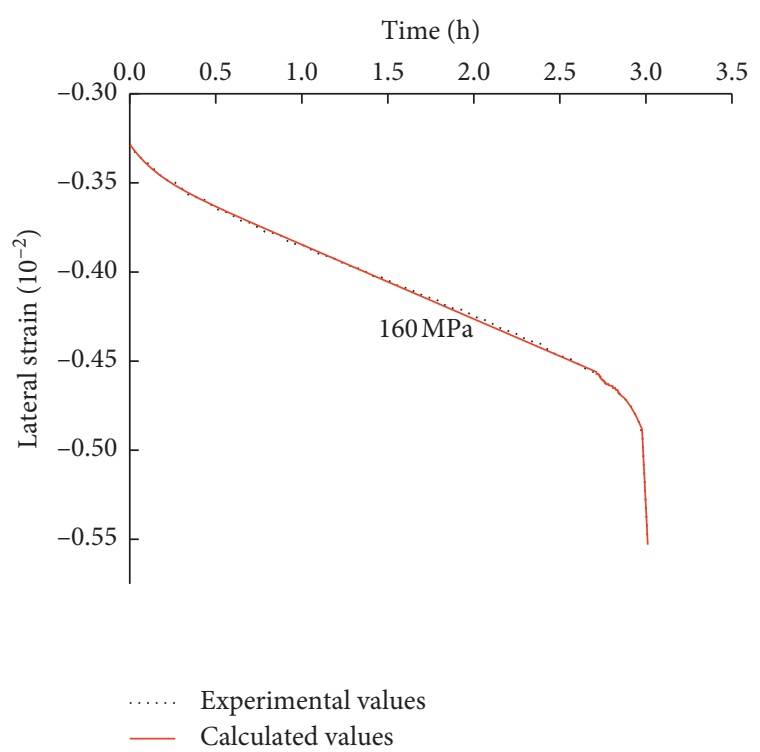

(b)

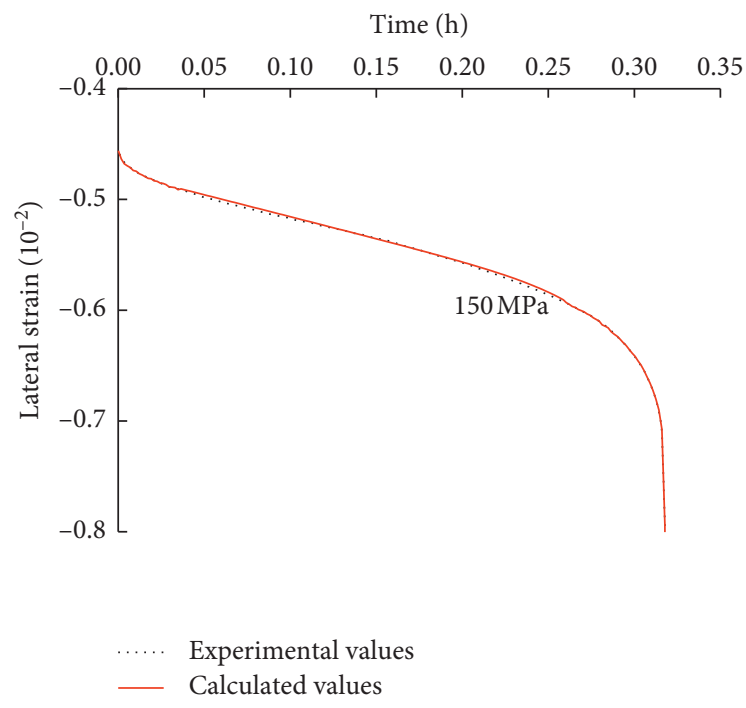

(c)

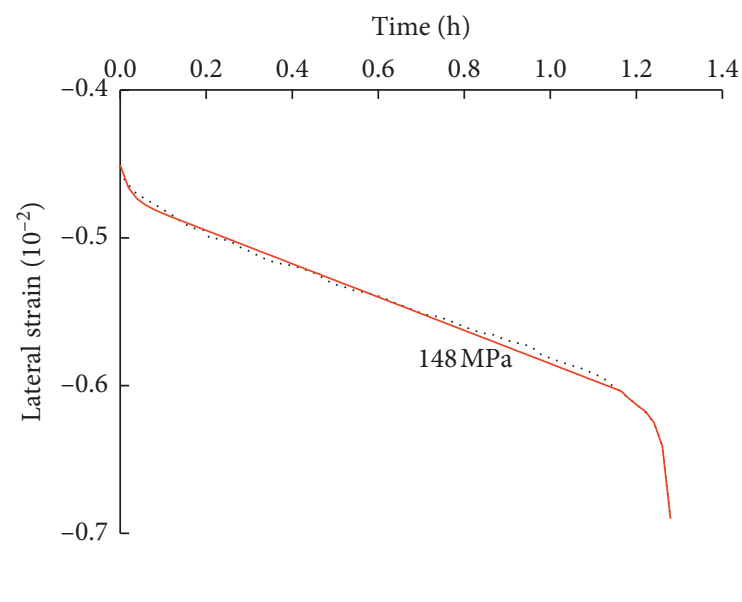

(d)

FiguRe 6: Relationships between the experimental and the calculated values at the failure stress level. (a) $0^{\text {th }}$ cycle. (b) $2^{\text {nd }}$ cycle. (c) $6^{\text {th }}$ cycle. (d) $10^{\text {th }}$ cycle. 


$$
\varepsilon_{1}= \begin{cases}\frac{\sigma_{1}-\sigma_{3}}{3 G_{1}\left(1-d_{E N 1}\right)}+\frac{\sigma_{1}+2 \sigma_{3}}{9 K\left(1-d_{E N 1}\right)}+\frac{\sigma_{1}-\sigma_{3}}{3 G_{2}\left(1-d_{E N 2}\right)}\left(1-e^{-\left(G_{2}\left(1-d_{E N 2}\right) / \eta_{1}\left(1-d_{\eta N 1}\right)\right) t}\right), & \sigma_{1}-\sigma_{3}<\sigma_{s}, \\ \frac{\sigma_{1}-\sigma_{3}}{3 G_{1}\left(1-d_{E N 1}\right)}+\frac{\sigma_{1}+2 \sigma_{3}}{9 K\left(1-d_{E N 1}\right)}+\frac{\sigma_{1}-\sigma_{3}}{3 G_{2}\left(1-d_{E N 2}\right)}\left(1-e^{-\left(G_{2}\left(1-d_{E N 2}\right) / \eta_{1}\left(1-d_{\eta N 1}\right)\right) t}\right)+\frac{\sigma_{1}-\sigma_{3}-\sigma_{s}}{3 \eta_{2}\left(1-d_{\eta N 2}\right)} t, & \sigma_{1}-\sigma_{3} \geq \sigma_{s}, t<t_{0}, \\ \frac{\sigma_{1}-\sigma_{3}}{3 G_{1}\left(1-d_{E N 1}\right)}+\frac{\sigma_{1}+2 \sigma_{3}}{9 K\left(1-d_{E N 1}\right)}+\frac{\sigma_{1}-\sigma_{3}}{3 G_{2}\left(1-d_{E N 2}\right)}\left(1-e^{-\left(G_{2}\left(1-d_{E N 2}\right) / \eta_{1}\left(1-d_{\eta N 1}\right)\right) t}\right)+\frac{\sigma_{1}-\sigma_{3}-\sigma_{s}}{3 \eta_{2}\left(1-d_{\eta N 2}\right)} t_{0}+\frac{\sigma_{1}-\sigma_{3}-\sigma_{s}}{3 \eta_{s}(1-D)\left(1-d_{\eta N 3}\right)}\left(t-t_{0}\right), & \sigma_{1}-\sigma_{3} \geq \sigma_{s}, t \geq t_{0} .\end{cases}
$$

\section{Parameter Identification and Verification}

The Levenberg-Marquardt method for nonlinear leastsquares curve fitting was used to verify the nonlinear creep model (considering the effect of the water-rock interaction). Besides, the sandstone rock data were identified by using the software called 1stOpt as shown in Table 1. The results are shown in Table 1.

From Table 1, one can see a strong correlation between the experimental and the predicted values due to the modification of a nonlinear constitutive model. The relationships between the experimental and the computed values are presented in Figures 5 and 6.

\section{Conclusion}

(1) The creep test results of sandstone under water-rock interaction show that the mechanical properties of sandstone continue to deteriorate with the increase of the water-rock interaction period. For the evaluation of the long-term strength of the rock mass under the action of water, it is very important to consider the damage of the water-rock interaction. Therefore, this paper introduces the water-rock interaction damage variable and establishes the consideration of the water-rock interaction damage creep model.

(2) When the stress level is higher than the failure stress level, the model can describe the nonlinearly accelerated creep characteristics of the rock. The Levenberg-Marquardt method for nonlinear least-squares curve fitting was used to identify the creep parameters of the sandstone rock. The predicted values were in a very good agreement with the experimental values.

(3) The strong correlations between the predicted and the experimental results show the effectiveness of the introduced constitutive model to capture the degradation behavior of a sandstone rock under the water-rock interactions.

(4) The introduced creep constitutive model of a sandstone rock is a powerful tool to scrutinize the rheological characteristics of the rock mass in the reservoir bank slope.

\section{Data Availability}

The Excel data used to support the findings of this study are available from the corresponding author upon request.

\section{Conflicts of Interest}

The authors declare that they have no conflicts of interest.

\section{Acknowledgments}

This study was supported by the Engineering Research Center of the Ministry of Education for the Ecological Environment of the Three Gorges Reservoir Area Open Foundation (no. KF2019-07), National Natural Science Foundation of China (nos. 51809151, 51979218, and U1965107), Natural Science Foundation of Shaanxi Province (no. 2018JM5118), Open Fund of Key Laboratory of Ministry of Education (no. 2017KDZ01), and China Postdoctoral Fund (no. 2017M613167).

\section{References}

[1] X. R. Liu, Y. Fu, and Y. X. Wang, "Deterioration rules of shear strength of sand rock under water-rock interaction of reservoir," Chinese Journal of Geotechnical Engineering, vol. 30, no. 9, pp. 1298-1302, 2008, in Chinese.

[2] Y. Wang, Q. N. Qiao, and J. L. Li, "The effect of initial creep damage on unloading failure properties of sandstone from macro-mesoscopic perspective," Periodica Polytechnica Civil Engineering, vol. 63, no. 4, pp. 1004-1015, 2019.

[3] M. Prasad and M. H. Manghnani, "Effects of pore and differential pressure on compressional wave velocity and quality factor in Berea and Michigan sandstones," Geophysics, vol. 62, no. 4, pp. 1163-1176, 1997.

[4] H. F. Deng, J. L. Li, and C. J. Deng, "Research on secondary porosity changing law of sandstone under the "saturation-air dry" cycles," Rock and Soil Mechanics, vol. 33, no. 2, pp. 483-488, 2012.

[5] Q. Jiang, H. Deng, J. Li et al., "The degradation effect and mechanism by water-rock interaction in the layered sandstone in the Three Gorges reservoir area," Arabian Journal of Geosciences, vol. 12, p. 722, 2019.

[6] W. W. Mo and P. Xu, "Research advances on the influences of reservoir water level fluctuation on slope stability," Chinese Journal of Underground Space \& Engineering, vol. 2, no. 6, pp. 997-1002, 2006.

[7] B. Li and C. W. Liu, "Experimental study on the creep characteristics of sandstone under water pressure environment," Advanced Engineering Sciences, no. 49, pp. 119-124, 2017.

[8] Y. Wang, J. L. Li, and Y. Zuo, "Rheological experimental study on soft rock of dam foundation and analysis on its long-term stability," Water Resources and Hydropower Engineering, vol. 46, no. 12, pp. 114-117, 2015. 
[9] Z. Wang, K. Yin, W. Jian et al., "Experimental study on rheological behaviors of wanzhou red sandstone in three Gorges reservoir area," Chinese Journal of Rock Mechanics \& Engineering, vol. 27, no. 4, pp. 840-847, 2008.

[10] G. Liu, X. Huang, and J. Pang, "The uniaxial creep characteristics of red sandstone under dry-wet cycles," Advances in Civil Engineering, vol. 2020, no. 1, pp. 1-13, 2020.

[11] G. N. Boukharov, M. W. Chanda, and N. G. Boukharov, "The three processes of brittle crystalline rock creep," International Journal of Rock Mechanics and Mining Sciences \& Geomechanics Abstracts, vol. 32, no. 4, pp. 325-335, 1995.

[12] Y. Fujii, T. Kiyama, Y. Ishijima, and J. Kodama, "Circumferential strain behavior during creep tests of brittle rocks," International Journal of Rock Mechanics and Mining Sciences, vol. 36, no. 3, pp. 323-337, 1999.

[13] K. Shin, S. Okubo, K. Fukui, and K. Hashiba, "Variation in strength and creep life of six Japanese rocks," International Journal of Rock Mechanics and Mining Sciences, vol. 42, no. 2, pp. 251-260, 2005.

[14] B. X. Yuan, M. Sun, L. Xiong, Q. Z. Luo, S. P. Pradhan, and H. Z. Li, "Investigation of 3D deformation of transparent soil around a laterally loaded pile based on a hydraulic gradient model test," Journal of Building Engineering, vol. 28, no. 3, Article ID 101024, 2020.

[15] B. X. Yuan, L. Xiong, L. Zhai et al., "Transparent synthetic soil and its application in modeling of soil-structure interaction using optical system," Frontiers in Earth Science, vol. 7, p. 276, 2019.

[16] B. X. Yuan, M. Sun, Y. X. Wang, L. H. Zhai, and Q. Z. Luo, "Full 3D displacement measuring system for 3D displacement field of soil around a laterally loaded pile in transparent soil," International Journal of Geomechanics, vol. 19, no. 5, Article ID 04019028, 2019.

[17] D. Lockner, "Room temperature creep in saturated granite," Journal of Geophysical Research: Solid Earth, vol. 98, no. B1, pp. 475-487, 1993.

[18] H. Zhu and B. Ye, "Experimental study on mechanical properties of rock creep in saturation," Chinese Journal of Rock Mechanics \& Engineering, vol. 21, no. 12, pp. 1791-1796, 2002.

[19] Y. Li, W. Zhu, S. Bai et al., "Uniaxial experimental study on rheological properties of granite in air-dried and saturated states," Chinese Journal of Rock Mechanics \& Engineering, vol. 22, no. 10, pp. 1673-1677, 2003.

[20] G. Liu, Y. Hu, F. Chen et al., "Rheological property of soft rock under multiaxial compression and its effect on design of arch dam," Chinese Journal of Rock Mechanics \& Engineering, vol. 23, no. 8, pp. 1237-1241, 2004.

[21] L. Liu, G.-M. Wang, J.-H. Chen, and S. Yang, "Creep experiment and rheological model of deep saturated rock," Transactions of Nonferrous Metals Society of China, vol. 23, no. 2, pp. 478-483, 2013.

[22] H. F. Deng et al., "Creep degradation mechanism by waterrock interaction in the red-layer soft rock," Arabian Journal of Geosciences, vol. 9, no. 12, p. 601, 2016.

[23] D. Grgic, "Constitutive modelling of the elastic-plastic, viscoplastic and damage behaviour of hard porous rocks within the unified theory of inelastic flow," Acta Geotechnica, vol. 11, no. 1, pp. 95-126, 2016.

[24] H. C. Yu, H. D. Liu, Z. Q. Huang, and G. C. Shi, "Experimental study on time-dependent behavior of silty mudstone from the Three Gorges Reservoir Area, China," KSCE Journal of Civil Engineering, vol. 21, no. 3, pp. 715-724, 2017.
[25] Z. Yu, X. U. Wei-Ya, G. U. Jin-Jian et al., "Triaxial creep tests of weak sandstone from fracture zone of high dam foundation," Journal of Central South University, vol. 20, no. 009, pp. 2528-2536, 2013.

[26] H. Z. Liu, H. Q. Xie, J. D. He, M. L. Xiao, and L. Zhuo, "Nonlinear creep damage constitutive model for soft rocks," Mechanics of Time-dependent Materials, vol. 21, no. 1, pp. 73-96, 2016.

[27] H. Ming, X. R. Liu, and D. Tao, "Numerical calculation of time effect deformations of tunnel surrounding rock in terms of water degradation," Rock \& Soil Mechanics, vol. 33, no. 6, pp. 1876-1882, 2012.

[28] X. Liu, X. Liu, T. Wang et al., "Creep model of low-grade metamorphic slate considering moisture degradation effect," Chinese Journal of Rock Mechanics \& Engineering, vol. 33, no. 12, pp. 2384-2389, 2014.

[29] B. Yan, Q. Guo, F. Ren, and M. Cai, "Modified Nishihara model and experimental verification of deep rock mass under the water-rock interaction," International Journal of Rock Mechanics and Mining Sciences, vol. 128, Article ID 104250, 2020.

[30] Z. Luo, J. Li, Q. Jiang et al., "Effect of the water-rock interaction on the creep mechanical properties of the sandstone rock," Periodica Polytechnica Civil Engineering, vol. 62, no. 2, pp. 451-461, 2018.

[31] W. Yu, L. I. Jian-Lin, H. F. Deng et al., "Investigation on unloading triaxial rheological mechanical properties of soft rock and its constitutive model," Rock \& Soil Mechanics, vol. 33, no. 11, pp. 3338-3344, 2012. 